\title{
Social Entrepreneurship Intention: Mindfulness Towards a Duality of Objectives
}

\author{
Andrés Chinchilla $^{1}$ (D) Mayte Garcia $^{1}$
}

Received: 25 April 2016/Accepted: 5 December 2016 / Published online: 9 January 2017

(C) Springer International Publishing 2017

\begin{abstract}
Social entrepreneurship is a phenomenon that has recently attracted the attention of scholars. It has been noted that social entrepreneurs develop skills that allow them to successfully cope with current challenges in both social and business settings. Given that attention to dual objectives requires greater focus and awareness, we suggest that mindfulness is an important characteristic of social entrepreneurship intention, along with entrepreneurial training and volunteering experience. This paper explores these relationships through a pilot study with 184 online surveys. The results show that there are positive relationships between mindfulness and entrepreneurship training and social entrepreneurship intention.
\end{abstract}

Keywords Social entrepreneurship $\cdot$ Mindfulness $\cdot$ Dual objectives

Globalization is an important phenomenon that continues to open new frontiers for business and society, yet countries continue to recover from a global crisis and from market imbalances that led not only to a social security crisis but also to economic struggle (International Labour Organization 2012). Consequently, it has been suggested that social entrepreneurship offers a perspective on how to cope effectively with these new situations, since social entrepreneurs are said to understand and address the needs of society while also recognizing opportunities to generate profits (Smith et al. 2012).

Regarding the study of social entrepreneurship and the dual objectives that it seeks to fulfill (social and economic), Dees (1998) describes the basic understanding that one must have to enter the social entrepreneurship field: the work of social entrepreneurs is developed in an even more complex and changing environment than that of commercial entrepreneurs because of

Andrés Chinchilla

andchinchilla@gmail.com

Mayte Garcia

mayte_garvi@hotmail.com

1 EGADE Business School, Tecnológico de Monterrey, Av. Eugenio Garza Laguera and Rufino Tamayo, Garza García, NL 66269, México 
the need to achieve a sustainable social impact while addressing the market. Tracey and Phillips (2007) describe the main challenge for social entrepreneurs as appropriately accomplishing their social and economic goals through the management of accountability, organizational identity and the double bottom line. In an extension of this research, Smith et al. (2012) present a model of social entrepreneurs' skill development based on empirical evidence from the classroom and from practice. In this model, one of the main skills to be developed is mindfulness of social and economic objectives to accomplish them in a balanced way. Additionally, this model (Smith et al. 2012) proposes mini-MBA training and direct experience of the social entrepreneurial organization's social impact.

Considering the importance of social entrepreneurship at the present time, as well as the complexity of the challenges that it faces, the purpose of this study is to complement the findings of previous research on the characteristics of social entrepreneurs. This goal is accomplished through a pilot study of the main characteristics necessary to fulfill the dual objectives of social entrepreneurship in a balanced way. Based on the conclusions of previous research, mindfulness is emphasized as one of these main characteristics. Social volunteering experience and entrepreneurial training are additional variables included in a model that explains the intentions of social entrepreneurship. We refer to intention because we seek to identify the motivations behind starting a social entrepreneurship project.

To achieve the objective mentioned above, this article is divided into two parts: (a) a literature review in which the major previous studies on the subject are discussed and the gap to be fulfilled in this study is identified; (b) a pilot study to identify the relationships between variables, ending with a discussion of further research proposals and the general conclusions of this study.

\section{Literature Review}

\section{Social Entrepreneurship}

Dees (1998) describes the characteristics of social entrepreneurs as follows: (a) they are change agents with a mission focused not only on private value but also on social value; (b) they recognize opportunities based on this mission; (c) they use continuous innovation, adaptation and learning in this recognition process; and (d) they act boldly while also being accountable. In addition to Dees' fundamental description, Tracey and Phillips (2007) define social entrepreneurship as the creation of an enterprise that has a social purpose, and thus, it involves both commercial viability and social construction. In achieving these dual objectives, there are three key challenges for the education of social entrepreneurs: managing accountability to properly respond to all stakeholders, managing the double bottom line to balance commercial and social objectives, and managing identity with a clear stance on social and economic objectives.

In light of previous studies describing and explaining social entrepreneurs' behaviors and skills, Smith et al. (2012) conducted a study based on paradox research in which they show that accepting, differentiating and integrating social and economic objectives are key leadership skills to be developed by social entrepreneurs. Moreover, in this study (Smith et al. 2012), the authors present specific skills and pedagogical tools to develop these main skills based on award-winning social entrepreneurship development processes in the field and in classroom settings. The diverse skills noted in this research include mindfully attending to social and 
economic objectives is addressed, and direct social impact experience and mini-MBA program training are examples of pedagogical tools used to develop this skill. Thus, empirical validation of the orientation toward this skill (mindfulness) and these pedagogical tools (social impact experience and entrepreneurship training), as presented in this model (Smith et al. 2012), would be beneficial and would complement previous explanations of the skills and development characteristics of social entrepreneurship.

In addition to this contribution (Smith et al. 2012), in an empirical study with a sample of college and undergraduate students, Nga and Shamuganathan (2010) sought to determine whether personality traits and demographic factors influence social entrepreneurial start-up intentions. To measure personality, the authors used the big five personality traits and tested their hypothesis using multiple regression; to measure intention, they used a questionnaire that included social vision, financial returns, innovation, sustainability and social networks to measure the components of social entrepreneurship; to determine the validity of this instrument developed from the literature, they used exploratory factor analysis. The main conclusions of the study (Nga and Shamuganathan 2010) were that the personality characteristics of agreeableness, openness and conscientiousness positively influence the social dimensions, and specifically, agreeableness positively influences all dimensions of social entrepreneurship intention.

Based on the contributions presented above, it is suggested that the development of knowledge of social entrepreneurship can be directed toward understanding the roles that mindfulness orientation, social volunteering experience, and entrepreneurship training play in social entrepreneurship intention. The next section provides an overview of the characteristics of mindfulness and social entrepreneurship.

\section{Mindfulness}

Mindfulness is a concept developed in eastern traditions, defined as devoting one's complete attention to the experiences occurring in the present moment in a non-judgmental or accepting way, resulting in wisdom, insight and compassion (Brown and Ryan 2003). It also helps influence one's degree of consciousness and whether one acts on automatic pilot or is truly aware of his or her surroundings (Baer et al. 2006). In a cross-level review by Sutcliffe et al. (2016), two bodies of research on mindfulness were identified. The first refers to individual mindfulness and the second to collective mindfulness. The difference is based on individual awareness vs. collective capabilities. Numerous definitions and studies have been developed for both streams of research. For individual mindfulness, the general definition includes present-moment awareness of internal and external elements. For collective mindfulness, five interrelated processes were identified: (a) preoccupation with failure, (b) reluctance to simplify interpretations, (c) sensitivity to operations, (d) commitment to resilience, and (e) deference to expertise (Weick and Sutcliffe 2006).

Previous studies have focused on how to develop individual mindfulness, and a variety of studies have referred to meditation. The effects of mindfulness on outcomes such as well-being and performance have also been identified (Sutcliffe et al. 2016). However, we suggest that further research is needed to advance understandings of the role of mindfulness in other phenomena, such as social entrepreneurship.

The first characteristic of social entrepreneurship defined by Dees (1998) is a focus on the dual mission of creating economic and social value and becoming change agents. Given the different objectives of social entrepreneurs, alignment between goals and incentives is 
considerably more complex and presents a greater challenge for social than for commercial entrepreneurship (Austin et al. 2006). Smith et al. (2012) propose a paradoxical leadership model for social entrepreneurs in which one of the main arguments is that social entrepreneurs need to learn to mindfully attend to the distinctions between commercial and social objectives and that this mindfulness can be attained through divergent thinking exercises. According to Weick and Sutcliffe (2006), organizational mindfulness involves an awareness of the individual complexities and faculties involved in decision-making, evaluating circumstances, and considering alternatives, which also reveals that mindfulness can bring awareness of the intention to accomplish dual objectives. Therefore, it can be expected that an individual's mindfulness orientation would explain her or his degree of social entrepreneurship intention.

The second characteristic is the recognition of new opportunities based on the mission. Entrepreneurs need high levels of alertness to recognize connections between events and trends that reveal business opportunities (Baron 2006). According to Austin et al. (2006), social entrepreneurs have a wide variety of opportunities given all the different social needs that exist, although the combination of internal and external factors is the basis for the detection of opportunities. For instance, entrepreneurs' personal experience combines with social needs to identify the ideas and innovations that can create the desired social impact (Baron 2006). An important element found across different definitions of mindfulness is that attention is not placed solely on external events and the environment; there is also internal awareness of one's emotions and thoughts (Perrini and Vurro 2006). Therefore, the internal and external awareness derived from mindfulness allows for better recognition of opportunities. Once opportunities have been identified, unexpected problems can also arise during the implementation process. For example, social entrepreneurship enterprises may be forced into growth even if such growth has not been considered or planned as a way of meeting social needs and generating greater impact (Austin et al. 2006). According to Weick and Sutcliffe (2006), mindfulness allows entrepreneurs to focus on comprehension of emerging threats and on factors that may interfere with such comprehension; it also permits the consideration of problems from an inter-relational perspective, using the adaptation characteristic to address those threats. This description is thought to fulfill the fundamental criteria of recognizing and following new opportunities, as defined by Dees (1998).

The third characteristic refers to continuous innovation. For entrepreneurs, the willingness to innovate is inherent, it is the way they are (Austin et al. 2006). For social entrepreneurs, innovation is seen not only in their recognition of opportunities and in their development of a new program, service or product but also in the assurance of resources alongside the creation of social value (Dees 1998). Langer (1989) pioneered the construction of mindfulness adapted to a western perspective, defining this term as a cognitive-information processing framework characterized by novelty seeking, engagement, novelty production and flexibility, which fulfill the fundamental aspects of continuous innovation, adaptation and learning. Vogus and Welbourne (2003) propose that organizational mindfulness is related to innovation. In the case of business schools, mindfulness allows market innovation, such as the development of new degrees and programs, more careful attention to different stakeholders as well as focusing on higher-order needs such as the well-being of students and societies (Vogus and Sutcliffe 2012). These aspects can be translated into social entrepreneurship given that they develop novel ideas for the market and that attention is placed on higher-order needs. At the same time, commitment to resilience as a process of collective mindfulness is defined as the cultivation of the capabilities to adapt, improvise, and cope with unexpected events, and it can be associated 
with the high tolerance for ambiguity and management of risks that social entrepreneurs need (Dees 1998).

Finally, the fourth characteristic refers to acting boldly while remaining accountable. Acting boldly refers to taking calculated risks as well as to doing more with less by leveraging limited resources through collaboration (Dees 1998). These characteristics are related to collective mindfulness, specifically to the process of preoccupation with failure that leads to acting carefully through reasonable risks. Tetlock (1983) found that accountability leads to more complex information processing, where the awareness and attention that characterize mindfulness are highly relevant to processing such complexity. Studies that analyze collective mindfulness and other positive organizational outcomes, such as effective resource allocation and reliability, are most commonly performed in contexts characterized by high complexity and dynamism (Sutcliffe et al. 2016), as in the environment of social entrepreneurship. Thus, as the literature and previous studies have found, mindfulness can play a significant role in social entrepreneurship.

\section{Social Volunteering Experience and Entrepreneurship Training}

According to Pache and Chowdhury (2012), social entrepreneurs need to be aware of social welfare, commercial, and public sector logics so that they can represent such competing logics and in turn combine them to create innovative hybrid strategies. In another study (Smith et al. 2012), direct social impact experience and mini-MBA training are considered key pedagogical tools for developing the skills needed by social entrepreneurs. Therefore, the social welfare and public sector understandings that social volunteering experience can provide, as well as the commercial logics learned through entrepreneurship training, are appropriate variables that complement a model that attempts to explain social entrepreneurship intention. Table 1 presents an overview of the characteristics of social entrepreneurship and the identified related variables. Given the theoretical links among these variables, along with the effects of mindfulness on social entrepreneurship, we designed a pilot study to provide further evidence and a deeper understanding of the relationships among the studied variables. The next section describes the methodology of this study.

\section{Proposed Model and Methodology}

The sample for this study consisted of two different groups. One group consisted of students from a private university in Mexico who were enrolled in an entrepreneurship course. The second group consisted of volunteers with a civil organization who had at least an undergraduate degree and were also from Mexico. The participants in the first group, the university students, were required to develop a business plan for a project as part of the entrepreneurship course. They also had to participate in an entrepreneurship national fair attended by investors from around the country looking for opportunities to build financial wealth; the fair provided an opportunity to compete for funds for their project. The second group, the volunteers with an entrepreneurial organization focused on the creation of social value, was directly involved in accomplishing the organization's social mission. The selection of these two sample groups provided heterogeneity and allowed for controlling for the variables of social experience and entrepreneurial training. An online questionnaire was developed to collect the data. The online survey approach was useful to collect data from the volunteers, who live in different states in 
Mexico. However, the response rate from students was quite low (6.7\%), and to increase the number of responses, paper surveys were distributed during class time. This resulted in a final usable sample of 74 social volunteers and 110 students, for a total sample of 184 . Please see Tables 1 and 2 for more detailed descriptions of each group in the sample.

\section{Measures}

Mindfulness The nine-item, one-factor model from the Langer Mindfulness/Mindlessness scale was used. This single-factor scale has shown a better fit than have two- and four-factor models (Haigh et al. 2011). A 5-point Likert scale was used to identify how well each of the statements described respondents, ranging from "Not at all like me" to "Just like me".

Social volunteering and entrepreneurial training Social volunteering experience was measured as a "dummy" variable indicating whether the individual had any experience performing social welfare activities without being economically rewarded. The entrepreneurship training variable, also measured as a "dummy" variable, indicates whether the individual had previous experience in undergraduate entrepreneurship courses with the objective of developing the skills of recognizing opportunities and conceiving viable business models to maximize economic value generation.

Control Variables A demographic variable, age, was considered as a control variable given the possible age differences between students and volunteers (Table 3).

Table 1 Relationship between social entrepreneurial characteristics and independent variables

\begin{tabular}{|c|c|c|}
\hline Social entrepreneur's characteristics & Definition (Dees 1998) & $\begin{array}{l}\text { Related variable(s) } \\
\text { identified }\end{array}$ \\
\hline Change agents in the social sector & $\begin{array}{l}\text { Make an important change by solving the } \\
\text { causes of social problems }\end{array}$ & $\begin{array}{l}\text { Mindfulness } \\
\text { Social volunteering } \\
\quad \text { experience }\end{array}$ \\
\hline $\begin{array}{l}\text { Adopting a mission to create and sustain } \\
\text { social and private value }\end{array}$ & $\begin{array}{l}\text { Balance profit seeking and creating social } \\
\text { value }\end{array}$ & $\begin{array}{l}\text { Mindfulness } \\
\text { Social volunteering } \\
\quad \text { experience } \\
\text { Entrepreneurship } \\
\quad \text { training }\end{array}$ \\
\hline $\begin{array}{l}\text { Recognizing and following new } \\
\text { opportunities }\end{array}$ & $\begin{array}{l}\text { Recognize opportunities by differentiating } \\
\text { what works and what does not }\end{array}$ & $\begin{array}{l}\text { Mindfulness } \\
\text { Entrepreneurship } \\
\text { training }\end{array}$ \\
\hline Continuous innovation & Develop new approaches & Mindfulness \\
\hline Continuous adaptation & Be flexible in different situations & Mindfulness \\
\hline Continuous learning & Improve using new knowledge & Mindfulness \\
\hline Act boldly & Do more with less & $\begin{array}{l}\text { Mindfulness } \\
\text { Entrepreneurship } \\
\quad \text { training }\end{array}$ \\
\hline High sense of accountability & $\begin{array}{l}\text { Meet everyone's the social and economic } \\
\text { needs }\end{array}$ & $\begin{array}{l}\text { Mindfulness } \\
\text { Social volunteering } \\
\quad \text { experience } \\
\text { Entrepreneurship } \\
\quad \text { training }\end{array}$ \\
\hline
\end{tabular}


Table 2 Descriptive statistics (student group)

\begin{tabular}{lllll}
\hline & Frequency & Percent & Valid percent & Cumulative percent \\
\hline Age & & & & \\
$\quad 19-21$ & 29 & 27.4 & 27.4 & 27.4 \\
$22-23$ & 73 & 68.9 & 68.9 & 96.2 \\
$\quad$ Over 23 & 4 & 3.8 & 3.8 & 100 \\
Total & 106 & 100 & 100 & \\
Gender & & & & 50.9 \\
$\quad$ Male & 54 & 50.9 & 50.9 & 100 \\
$\quad$ Female & 52 & 49.1 & 49.1 & \\
Total & 106 & 100 & 100 & 46.2 \\
Discipline & & & & 77.4 \\
$\quad$ Business administration and finance & 49 & 46.2 & 46.2 & 100 \\
$\quad$ Engineering & 33 & 77.4 & 77.4 & \\
$\quad$ Other & 24 & 22.6 & 22.6 & \\
Total & 106 & 100 & 100 & 79.8 \\
Origin state & & & & \\
$\quad$ Northern & 71 & 67 & 79.8 & \\
$\quad$ Other & 18 & 17 & 20.2 & \\
$\quad$ Not specified & 17 & 16 & & \\
Total & 106 & 100 & & \\
\hline
\end{tabular}

\section{Data Analysis}

Based on previous studies focused on the description and explanation of social entrepreneurship, a model that explains social entrepreneurship intention (SEntI) with mindfulness orientation (MO), social volunteering experience (SVExp), and entrepreneurship training (EntT) is

Table 3 Descriptive statistics (social volunteers group)

\begin{tabular}{|c|c|c|c|c|}
\hline & Frequency & Percent & Valid percent & Cumulative percent \\
\hline \multicolumn{5}{|l|}{ Age } \\
\hline $21-30$ & 6 & 10.2 & 10.2 & 10.2 \\
\hline $31-40$ & 11 & 18.6 & 18.6 & 28.8 \\
\hline $41-50$ & 24 & 40.7 & 40.7 & 69.5 \\
\hline Over 50 & 18 & 30.5 & 30.5 & 100 \\
\hline Total & 59 & 100 & 100 & \\
\hline \multicolumn{5}{|l|}{ Gender } \\
\hline Male & 14 & 23.7 & 23.7 & 23.7 \\
\hline Female & 45 & 76.3 & 76.3 & 100 \\
\hline Total & 59 & 100 & 100 & \\
\hline \multicolumn{5}{|l|}{ Occupation } \\
\hline Housewife & 13 & 22 & 22 & 22 \\
\hline Business owner & 10 & 17 & 17 & 39 \\
\hline Educator & 8 & 14 & 14 & 53 \\
\hline Other & 28 & 47 & 47 & 100 \\
\hline Total & 59 & 100 & 100 & \\
\hline \multicolumn{5}{|l|}{ Origin state } \\
\hline Northern & 34 & 58 & 58 & 58 \\
\hline Central & 13 & 22 & 22 & 80 \\
\hline Western & 9 & 15 & 15 & 95 \\
\hline Other & 3 & 5 & 5 & 100 \\
\hline Total & 59 & 100 & 100 & \\
\hline
\end{tabular}


proposed. To identify relationships between variables, multiple regression analysis was conducted.

As described in the first section, social entrepreneurship implies dual objectives (generation of both social value and economic value); therefore, this study attempts to provide an alternative form of measuring this duality. To accomplish this objective, the social vision and financial returns dimensions from the Nga and Shamuganathan (2010) scale are taken as a base.

Concerning the measurement instrument, in the calculation of an individual's social entrepreneurship intention, it was determined that considering only the mean of both dimensions' answers would "hide" variation in the final calculation (i.e., if someone gave high answers to all financial returns items and low answers to all social items, then the mean would be the same as that of someone who answered in the middle of the scale for both dimensions). The need to differentiate such cases and thus correct the calculation by considering this possible variation was identified.

The standard deviation is a measure of statistical dispersion if the center of the data is measured about the mean (Dodge 2003); thus, the measurement of the mean answer on the scale was corrected by subtracting the standard deviation. In this way, the mean of social entrepreneurship intention is adjusted to reduce the variance between both objectives. Observing the data, it was also determined that this calculation is closest to reflecting the intention of scoring highly in both dimensions (social and financial).

It is also important to note that the same number of items was considered for both social vision and financial return and that such items semantically represented the extreme intentions corresponding to each dimension.

\section{Preliminary Findings}

\section{Model Estimation and Inference}

The regression results show that the $\mathrm{MO}$ and EntT variables have a positive influence on SEInt. MO shows a regression coefficient of 0.27 ; EntT, a regression coefficient of 0.59 . From this, it is inferred that for each one-point change on the MO Likert scale, a 0.27-point increase on the SEInt Likert scale occurs. Likewise, if an individual participated in an entrepreneurship training course, then her or his social entrepreneurship intention would increase 0.59 on the SEInt Likert scale.

In contrast, having social volunteering experience is associated with a decrease in the individual's social entrepreneurship intention; the regression coefficient for this variable showed that having social volunteering experience is associated with a decrease of 0.21 points on the SEInt Likert scale.

The model that was estimated to test the hypotheses presented above showed an (adjusted $R^{2}$ of 0.22 ), an acceptable value for this type of model.

To verify whether the influence of the entrepreneurship training variable is related to the age of the individual, variance inflation factors were obtained, showing acceptable indexes. See Table 4 for the results of the estimations obtained via multiple linear regression.

The multiple linear regression assumptions of heteroscedasticity, multicollinearity, and normality of errors were considered in order to obtain valid inferences. Regarding heteroscedasticity, a Breusch-Pagan test was performed to identify whether the estimated 
Table 4 Results of hypotheses testing for the social entrepreneurship intention model

\begin{tabular}{|c|c|c|c|}
\hline \multirow[t]{2}{*}{ Independent variable } & \multicolumn{3}{|c|}{ Social entrepreneurship intention } \\
\hline & & $B$ & $p$-Value \\
\hline Constant $\left(\beta_{0}\right)$ & & 1.27 & $0.01 * *$ \\
\hline Mindfulness orientation & & 0.27 & $0.01 * *$ \\
\hline Social volunteering experience & & -0.21 & $0.05 *$ \\
\hline Entrepreneurship training & & 0.59 & $0.00 * * *$ \\
\hline Adjusted $R^{2}$ & 0.22 & & \\
\hline
\end{tabular}

variance of errors was constant or dependent on the values of the independent variable (Breusch and Pagan 1979). Concerning the normality of errors assumption, a Jarque-Bera test was performed to verify that the skewness and kurtosis of the sample matched a normal distribution (Jarque and Bera 1987). Regarding multicollinearity, variance inflation factors were estimated to determine whether the independent variables in the models were highly correlated (Wooldridge 2009).

Thus, the preliminary findings from this study are the following: Mindfulness orientation and entrepreneurship training are significant predictors of social entrepreneurship intention. Mindfulness generates a higher degree of context awareness, as well as awareness of one's own strengths and weaknesses, while entrepreneurship training provides the tools to exploit the opportunities recognized through such awareness. In contrast, social volunteering experience is not required in order to have an intention of social entrepreneurship that focuses on the accomplishment of social and economic objectives; this confirms the argument of Smith et al. (2012) regarding the social entrepreneurship challenge, which outlines the risks of focusing on only social or economic objectives.

The main implications drawn from these conclusions are to include a strong entrepreneurship training program along with the development of mindfulness skills to help social entrepreneurs successfully fulfill their dual objectives.

\section{Research Limitations and Future Research Proposals}

Although the sample in this research includes individuals from various Mexican states, the majority of respondents $(63 \%)$ were from northern states. It is therefore suggested that contextualization of the results be considered for further research purposes. Regarding the model's accuracy, the normality of errors tests for the multiple linear regression assumptions indicated that improvements could be attained by considering a larger sample.

Concerning the model variables, the influence of the family environment of the individuals in the sample was not considered in the tests of the hypotheses, even though it may be a significant explanation for social entrepreneurship intentions. Additionally, it is suggested that research on social entrepreneurship intentions be developed over diverse periods of time during entrepreneurship training courses to produce a complete understanding of the overall impact of such courses. Additionally, research on the dependent variable (SEntI) should be developed, considering the specific categorization of personalities as predictors of this 
particular intention measurement. Finally, given the intentional connotation of the dependent variable and of the mindfulness variable, it is recommended that the study of mindfulness using alternative methods be pursued further, as this could provide behavioral insight into its measurement to verify whether its influence on social entrepreneurship intention is significant.

\section{References}

Austin, J., H. Stevenson, and J. Wei-Skillern. 2006. Social and commercial entrepreneurship: Same, different, or both? Entrepreneurship Theory and Practice 30(1): 1-22.

Baer, R., G. Smith, J. Hopkins, J. Krietemyer, and L. Toney. 2006. Using self-report assessment methods to explore facets in mindfulness. Assessment 13(1): 27-45.

Baron, R.A. 2006. Opportunity recognition as pattern recognition: How entrepreneurs "connect the dots" to identify new business opportunities. Academy of Management Perspectives 20(1): 104-119.

Breusch, T.S., and A.R. Pagan. 1979. Simple test for heteroscedasticity and random coefficient variation. The Econometric Society 47(5): 1287-1294. doi:10.2307/1911963.

Brown, K.W., and R.M. Ryan. 2003. The benefits of being present: Mindfulness and its role in psychological well-being. Journal of Personality and Social Psychology 84(4): 822-848.

Dees, J. G. 1998. The meaning of "social entrepreneurship." Comments and suggestions contributed from the Social Entrepreneurship Founders Working Group. Durham, NC: Center for the Advancement of Social Entrepreneurship, Fuqua School of Business, Duke University. Available at http://faculty.fuqua.duke. edu/centers/case/files/dees-SE.pdf.

Dodge, Y. 2003. The oxford dictionary of statistical terms. Oxford: Oxford University Press.

Haigh, E., M. Moore, T. Kashdan, and D. Fresco. 2011. Examination of the factor structure and concurrent validity of the Langer mindfulness/mindlessness scale. Assessment 18(1): 11-26.

International Labour Organization. 2012. World of Work Report: Better Jobs for a Better Economy. International Labour Office, International Institute for Labour Studies.

Jarque, C.M., and A.K. Bera. 1987. A test for normality of observations and regression residuals. International Statistical Review 55(2): 163-172.

Langer, E.J. 1989. Mindfulness. Cambridge: De Capo Press.

Nga, J., and G. Shamuganathan. 2010. The influence of personality traits and demographic factors on social entrepreneurship start up intentions. Journal of Business Ethics 95(2): 259-282.

Pache, A.C., and I. Chowdhury. 2012. Social entrepreneurs as institutionally embedded entrepreneurs: Toward a new model of social entrepreneurship education. Academy of Management Learning \& Education 11(3): 494-510. doi:10.5465/amle.2011.0019.

Perrini, F., and C. Vurro. 2006. Social entrepreneurship: Innovation and social change across theory and practice. In Social entrepreneurship, ed. J. Mair, J. Robinson, and K. Hockerts, 57-85. New York: Palgrave Macmillan.

Smith, W., M. Besharov, A. Wessels, and M. Chertok. 2012. A paradoxical leadership model for social entrepreneurs: Challenges, leadership skills, and pedagogical tools for managing social and commercial demands. Academy of Management Learning and Education 11(3): 463-478.

Sutcliffe, K.M., T.J. Vogus, and E. Dane. 2016. Mindfulness in organizations: A cross-level review. Annual Review of Organizational Psychology and Organizational Behavior 3: 55-81.

Tetlock, P.E. 1983. Accountability and complexity of thought. Journal of Personality and Social Psychology 45(1): 74.

Tracey, P., and N. Phillips. 2007. The distinctive challenge of educating social entrepreneurs: A postscript and rejoinder to the special issue on entrepreneurship education. Academy of Management Learning and Education 6(2): 267-271.

Vogus, T.J., and K.M. Sutcliffe. 2012. Organizational mindfulness and mindful organizing: A reconciliation and path forward. Academy of Management Learning \& Education 11(4): 722-735.

Vogus, T.J., and T.M. Welbourne. 2003. Structuring for high reliability: HR practices and mindful processes in reliability-seeking organizations. Journal of Organizational Behavior 24(7): 877-903.

Weick, K.E., and K.M. Sutcliffe. 2006. Mindfulness and the quality of organizational attention. Organization Science 17(4): 514-524.

Wooldridge, J.M. 2009. Introductory econometrics: A modern approach. Mexico: Thompson/South-Western CENGAGE-Learning. 